\title{
Using a Hybrid Neural System to Reveal Regulation of Neuronal Network Activity by an Intrinsic Current
}

\author{
Michael Sorensen, ${ }^{1,2}$ Stephen DeWeerth, ${ }^{1}$ Gennady Cymbalyuk, ${ }^{2}$ and Ronald L. Calabrese ${ }^{2}$ \\ ${ }^{1}$ Laboratory for Neuroengineering, Georgia Institute of Technology, Atlanta, Georgia 30332-0363, and 2Department of Biology, Emory University, Atlanta, \\ Georgia 30322
}

The generation of rhythmic patterns by neuronal networks is a complex phenomenon, relying on the interaction of numerous intrinsic and synaptic currents, as well as modulatory agents. To investigate the functional contribution of an individual ionic current to rhythmic pattern generation in a network, we constructed a hybrid system composed of a silicon model neuron and a heart interneuron from the heartbeat timing network of the medicinal leech. When the model neuron and a heart interneuron are connected by inhibitory synapses, they produce rhythmic activity similar to that observed in the heartbeat network. We focused our studies on investigating the functional role of the hyperpolarization-activated inward current $\left(I_{\mathrm{h}}\right)$ on the rhythmic bursts produced by the network. By introducing changes in both the model and the heart interneuron, we showed that $I_{\mathrm{h}}$ determines both the period of rhythmic bursts and the balance of activity between the two sides of the network, because the amount and the activation/deactivation time constant of $I_{\mathrm{h}}$ determines the length of time that a neuron spends in the inhibited phase of its burst cycle. Moreover, we demonstrated that the model neuron is an effective replacement for a heart interneuron and that changes made in the model can accurately mimic similar changes made in the living system. Finally, we used a previously developed mathematical model (Hill et al. 2001) of two mutually inhibitory interneurons to corroborate these findings. Our results demonstrated that this hybrid system technique is advantageous for investigating neuronal properties that are inaccessible with traditional techniques.

Key words: VLSI; hybrid systems analysis; silicon neurons; leech; h-current; half-center oscillator; model neurons; dynamic clamp

\section{Introduction}

Modeling and experiment have been viewed traditionally as separate, albeit complementary, fields. Neuronal models suggest new experimental directions, and experiments, in turn, suggest refinements to the models. Recent advances in technology, however, have facilitated the creation of models that operate in real time, allowing models to play a direct role in experiments (Yarom, 1991; Le Masson et al., 1999; Manor and Nadim, 2001). Numerous studies with the dynamic clamp, for example, have shown how the addition of a model conductance can affect the activity of a neuron or neuronal network (Sharp et al., 1993, 1996). Other studies have used real-time model neurons to investigate such phenomena as the role of feedback in thalamic circuits (Le Masson et al., 2002), period regulation in pacemaker networks (Nadim and Manor, 2001), and regularization of chaos in motor pattern-generating networks (Szucs et al., 2000). These approaches allow the investigator to perform experiments that would be impossible or prohibitively difficult with traditional neurophysiological techniques, while providing a biological realism and relevance not achievable through modeling alone.

Received Sept. 30, 2003; revised May 3, 2004; accepted May 3, 2004.

This work was supported by National Institutes of Health Grant NS043098. We thank Dr. Mario Simoni (RoseHulman University, Terre Haute, IN), who designed the silicon neuron used in this study.

Correspondence should be addressed to Dr. Ronald L. Calabrese, Department of Biology, Emory University, 1510 Clifton Road, Atlanta, GA 30322. E-mail: rcalabre@biology.emory.edu.

DOI:10.1523/JNEUROSCI.4449-03.2004

Copyright $\odot 2004$ Society for Neuroscience $\quad$ 0270-6474/04/245427-12\$15.00/0
Our primary focus is on understanding mechanisms of motor pattern generation. We have studied the network that paces the heartbeat of the medicinal leech (Calabrese et al., 1995). Two coupled oscillators in the third and fourth segmental ganglia generate the timing in this network. Each oscillator comprises two heart interneurons connected by reciprocal inhibitory synapses, a structure referred to as a half-center oscillator (Hill et al., 2003). These small networks produce rhythmic antiphasic bursts. When one neuron is active, it inhibits the activity of its partner; eventually, the inhibited neuron is released or escapes from inhibition and begins firing, inhibiting the first neuron. This first neuron then is released or escapes from inhibition, and the cycle repeats.

To understand the cellular mechanisms that underlie these oscillations, we have created a hybrid system consisting of a heart interneuron and a silicon neuron, a model of the heart interneuron implemented using custom microelectronic circuits (Simoni et al., 2002, 2004). The silicon neuron provides real-time operation and implements a version of the Hodgkin-Huxley formalism (Hodgkin and Huxley, 1952). This mechanistic approach to modeling facilitates investigation of biophysical properties underlying neuronal activity. When the silicon neuron and a heart interneuron are connected with reciprocal inhibitory synapses of appropriate strength, they form a hybrid half-center oscillator that produces oscillations remarkably similar to those seen in the living system.

We focused our experiments on the hyperpolarizationactivated inward current $\left(I_{\mathrm{h}}\right)$, which has been shown to exert 
Table 1. Silicon neuron current parameters

\begin{tabular}{|c|c|c|c|c|c|c|}
\hline $\begin{array}{l}\text { SiN } \\
\text { current }\end{array}$ & $\begin{array}{l}\text { Reversal potential } \\
E_{\text {ion }}(\mathrm{V})\end{array}$ & $\begin{array}{l}\text { Maximal conductance } \\
\bar{g}\left(10^{-9} \mathrm{~S}\right)\end{array}$ & $\begin{array}{l}\text { Half-activation } \\
\text { voltage (V) }\end{array}$ & $\begin{array}{l}\text { Half-inactivation } \\
\text { voltage }(\mathrm{V})\end{array}$ & $\begin{array}{l}\text { Activation time } \\
\text { constant } \tau_{\mathrm{m}}(\mathrm{sec})\end{array}$ & $\begin{array}{l}\text { Inactivation time } \\
\text { constant } \tau_{\mathrm{h}}(\mathrm{sec})\end{array}$ \\
\hline$I_{\mathrm{Na}}$ & 0.045 & 57.0 & -0.028 & -0.023 & 0 & 0.005 \\
\hline$I_{p}$ & 0.030 & 6.0 & -0.034 & & 0.034 & \\
\hline$I_{\mathrm{K} 1}$ & -0.059 & 70.0 & -0.030 & -0.020 & 0.01 & 0.5 \\
\hline$I_{\mathrm{K} 2}$ & -0.081 & 42.4 & -0.018 & & 0.25 & \\
\hline$I_{\mathrm{Ca}}$ & 0.134 & 2.4 & -0.045 & -0.050 & 0.086 & 2.5 \\
\hline$I_{\mathrm{h}}$ & -0.028 & 4.0 & -0.050 & & 2.0 & \\
\hline$I_{\text {leak }}$ & -0.060 & 8.0 & & & & \\
\hline
\end{tabular}

pacemaker effects in numerous vertebrate and invertebrate systems (Luthi and McCormick, 1998). By introducing changes in the maximal conductance $\left(\bar{g}_{\mathrm{h}}\right)$ and the activation/deactivation time constant $\left(\tau_{\mathrm{h}}\right)$ of $I_{\mathrm{h}}$, we reveal how $I_{\mathrm{h}}$ controls the period and burst duration of the heart interneurons in a heartbeat half-center oscillator. Moreover, by inducing similar changes in both model and heart interneurons, we demonstrate that the silicon neuron can serve as a replacement for a living heart interneuron; changes made to the silicon neuron can describe how similar changes in the living network affect the generation of rhythmic activity.

\section{Materials and Methods}

The silicon neuron was fabricated through an integrated-circuit brokerage service in the AMI Semiconductor (Pocatello, ID) $1.2 \mu \mathrm{m}$ process (MOSIS, Marina del Rey, CA). It was designed to produce electrical activity similar to a leech heart interneuron by emulating its major ionic currents (Table 1) with a Hodgkin-Huxley-like formalism (Hodgkin and Huxley, 1952; Simoni et al., 2004). The silicon neuron provides emulation of several currents contained in a previously published model of an oscillator heart interneuron (Hill et al., 2001): passive leak current $\left(I_{\text {leak }}\right)$; fast sodium current $\left(I_{\mathrm{Na}}\right)$; inactivating potassium current $\left(I_{\mathrm{K} 1}\right)$; slow, non-inactivating potassium current $\left(I_{\mathrm{K} 2}\right)$; persistent sodium current $\left(I_{\mathrm{P}}\right)$; slowly inactivating low-threshold calcium current $\left(I_{\mathrm{CaS}}\right)$; and hyperpolarization-activated inward current $\left(I_{\mathrm{h}}\right)$. The design, details, and many of the characteristics of the silicon neuron used in this study were described by Simoni et al. (2004). Parameter values of the silicon neuron were set using 16-bit, four-channel digital-to-analog converters (Analog Devices, Norwood, MA). Digital-to-analog converters were interfaced to a personal computer via PIC microcontrollers (Microchip, Chandler, AZ). A user interface and software to communicate with PIC microcontrollers was written with the Java programming language (Sun Microsystems, Santa Clara, CA). Membrane potential measurement of and current injection into the silicon neuron were accomplished by direct connection to the headstages of an Axoclamp-2A electrophysiology amplifier (Axon Instruments, Union City, CA). State variables were measured through a current preamplifier (Stanford Research System, Sunnyvale, CA). The canonical parameter values for the silicon neuron are shown in Table 1.

In voltage-clamp experiments on the silicon neuron, conductances were isolated by setting all other maximal conductances to $0 \mathrm{nS}$. For all activation variables, except $m_{\mathrm{h}}$, the membrane potential $\left(V_{\mathrm{m}}\right)$ was held at $-85 \mathrm{mV}$ and then stepped up to command potentials. Because $I_{\mathrm{h}}$ is hyperpolarization activated, $V_{\mathrm{m}}$ was held at $30 \mathrm{mV}$ and stepped down to command potentials. For currents possessing an inactivation variable, the time constants of activation were much faster than the time constant of inactivation, which allowed us to approximate the steady-state value of the current with its peak value. In currents with only activation variables, the current at the end of the command step was taken as the steady-state value. To analyze the inactivation variables, $V_{\mathrm{m}}$ was held at various holding potentials for a time sufficient to ensure that steady-state inactivation was reached, then stepped to a command potential of $50 \mathrm{mV}$. The peak value of the current was taken as the steady-state value. Current waveforms were fit to a first- or second-order exponential to assess the value of time constants.

Mathematical modeling was performed in the GENESIS simulation environment (Bower and Beeman, 1998). Two single-compartment isopotential heart interneurons connected by mutually inhibitory synapses were modeled. Differential equations were integrated using the exponential Euler method with a time step of $10^{-4} \mathrm{sec}$. For each experiment, simulation parameters were set to default values and $\bar{g}_{\mathrm{h}}$ was then changed. The simulation was run for $100 \mathrm{sec}$ for the activity to settle, and then $400 \mathrm{sec}$ of data were recorded. Details of the model structure and simulation parameters were described by Hill et al. (2001).

Leeches (Hirudo medicinalis) were obtained from a supplier (Leeches USA, Westbury, NY; and Biopharm, Burlington, NC) and maintained in artificial pond water at $15^{\circ} \mathrm{C}$. After the animals were anesthetized in ice-cold saline, individual ganglia were dissected and pinned ventral side up in Petri dishes lined with Sylgard (bath volume, $0.5 \mathrm{ml}$ ). The methods for preparing and maintaining leech ganglia and for identifying heart interneurons for electrophysiological recording have been described previously (Olsen and Calabrese, 1996) (Fig. 1).

The ganglionic sheath over the cell bodies was removed with fine microscissors or scalpels. Ganglia were superfused continuously with normal leech saline containing (in $\mathrm{mm}$ ) $115 \mathrm{NaCl}, 4 \mathrm{KCl}, 1.8 \mathrm{CaCl}_{2}, 10$ glucose, and 10 HEPES buffer, adjusted to $\mathrm{pH}$ 7.4. All experiments were performed on heart interneurons in an isolated midbody segmental ganglion 3 or 4 . Heart interneurons were isolated pharmacologically with $2.5 \times 10^{-4} \mathrm{M}$ bicuculline methiodide (Sigma, St. Louis, MO) added to normal saline. In some experiments, $2 \mathrm{~mm} \mathrm{CsCl}$ was added to the saline to block $I_{\mathrm{h}}$.

Heart interneurons were penetrated with sharp microelectrodes made from borosilicate glass tubes [ $1 \mathrm{~mm}$ outer diameter, $0.75 \mathrm{~mm}$ inner diameter; filled with $4 \mathrm{M}$ potassium acetate with $20 \mathrm{~mm} \mathrm{KCl}(20-35 \mathrm{M} \Omega)$; A-M Systems, Everett, WA]. Currents were injected using discontinuous single-electrode current clamp (Axoclamp 2A; Axon Instruments, Foster City, CA). Sample rates were between 2.5 and $3 \mathrm{kHz}$. The electrode potential was monitored on an oscilloscope to ensure that it had settled between current injection cycles. Only neurons with an input resistance $>60 \mathrm{M} \Omega$ were accepted. At the end of the experiment, microelectrodes were withdrawn from the cell, and only when the bath potential measured by the electrode was within the range $\pm 5 \mathrm{mV}$ were the data accepted.

Dynamic-clamp synapses were implemented according the following equations (Cymbalyuk et al., 2002a,b):

$$
\begin{gathered}
I_{\text {syn }}=\bar{g}_{\text {syn }} Y_{\text {post }} M_{\text {post }}\left(V_{\text {post }}-E_{\text {syn }}\right), \\
\frac{d X_{\text {post }}}{d t}=\frac{X_{\infty}\left(V_{\text {pre }}\right)-X_{\text {post }}}{\tau_{1}}, \\
\frac{d Y_{\text {post }}}{d t}=\frac{X_{\text {post }}-Y_{\text {post }}}{\tau_{2}}, \\
\frac{d M_{\text {post }}}{d t}=\frac{M_{\infty}\left(V_{\text {pre }}\right)-M_{\text {post }}}{0.2}, \\
M_{\infty}\left(V_{\text {pre }}\right)=0.1+\frac{0.9}{1+e^{-1000\left(V_{\text {pre }}+0.04\right)}}, \\
X_{\infty}\left(V_{\text {pre }}\right)=\frac{1}{1+e^{-1000\left(V_{\text {pre }}+0.01\right)},}
\end{gathered}
$$




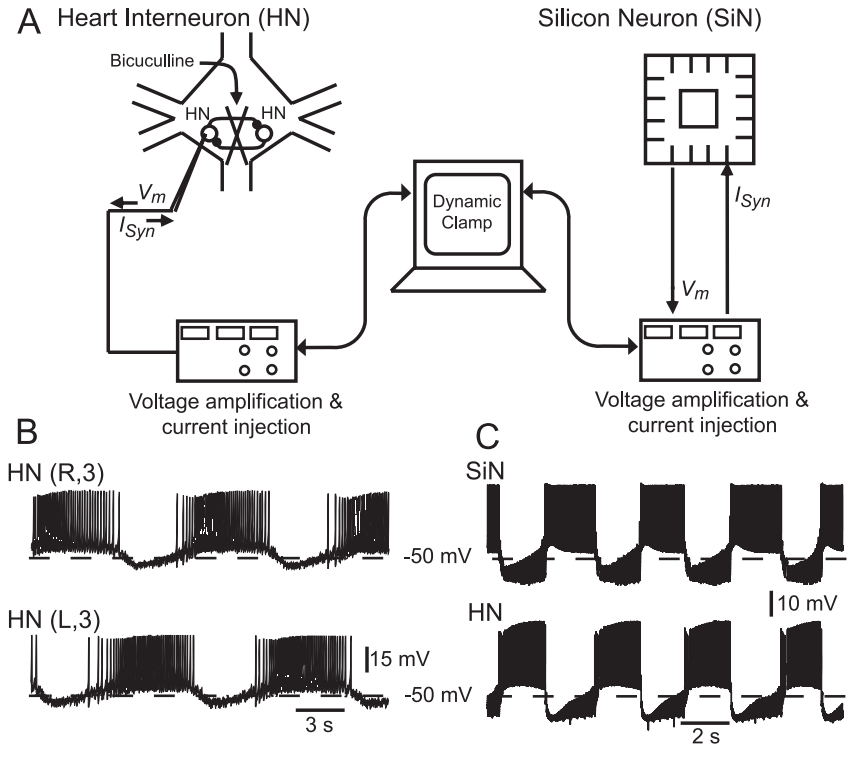

Figure 1. Design and activity of hybrid half-center oscillator. $A$, Heart interneurons (HN), in an isolated ganglion preparation, were pharmacologically isolated with bicuculline. Voltage/ current-clamp amplifiers were used for recording and current injection into heart interneurons and the silicon neuron (SiN). A single sharp microelectrode in discontinuous current-clamp mode was used for voltage recording and current injection into an isolated heart interneuron. Voltage recording and current injection into the silicon neuron were provided by direct connection to amplifier headstages (two-electrode current-clamp mode). Dynamic clamp provided real-time control signals to create artificial synapses between a heart interneuron and the silicon neuron. $B$, Activity of a living heart interneuron half-center oscillator in an isolated ganglion 3 (heart interneurons indexed by body side and ganglion number). C, Activity of a hybrid half-center oscillator.

where $\tau_{1}=0.002 \mathrm{sec}, \tau_{2}=0.011 \mathrm{sec}, \bar{g}_{\mathrm{syn}}=500 \mathrm{nS}$, and $E_{\mathrm{syn}}=$ $-0.062 \mathrm{~V}$.

Dynamic-clamp $I_{\mathrm{h}}$ was implemented as follows:

$$
\begin{gathered}
I_{\mathrm{h}}=\bar{g}_{\mathrm{h}} m_{\mathrm{h}}\left(V_{\mathrm{m}}-E_{\mathrm{h}}\right), \\
\frac{d m_{\mathrm{h}}}{d t}=\frac{m_{\infty \mathrm{h}}-m_{\mathrm{h}}}{\tau_{\mathrm{m}, \mathrm{h}}}, \\
m_{\infty}=\frac{1}{1+e^{180\left(V_{\mathrm{m}}+0.047\right)}+e^{500\left(V_{\mathrm{m}}+0.047\right)}}, \\
\tau_{\mathrm{m}, \mathrm{h}}=0.7+\frac{1.7}{1+e^{-100\left(V_{\mathrm{m}}+0.073\right)}},
\end{gathered}
$$

where $E_{\mathrm{h}}=-0.02 \mathrm{~V}$.

All dynamic-clamp calculations were performed on a dedicated realtime signal processing controller board (DS1104; DSPACE, Detroit, MI).

All experimental data were digitized and stored using pCLAMP software (Axon Instruments, Union City, CA). For both hybrid experiments and mathematical modeling, analyses of burst characteristics were performed off-line with scripts written in Matlab (MathWorks, Natick, $\mathrm{MA}$ ). Action potentials (spikes) were detected by determining when the membrane potential rose and then fell across a threshold of $-20 \mathrm{mV}$. If this sequence of two crossings occurred with an interval shorter than 1 $\mathrm{msec}$, the event was taken to be spurious because of digitization error or noise and was discarded. All other such events were considered to be spikes. The time of occurrence of the spike was taken as the time when the maximum membrane potential was reached. This method was verified by eye for $630 \mathrm{sec}$ of recorded data; in that data, all spikes had a width of at least $2 \mathrm{msec}$ above $-20 \mathrm{mV}$, and no spurious events registered as spikes. For all detected spikes in a continuous record, the mean and SD of the interspike interval (ISI) was calculated. ISIs $>0.5 \mathrm{sec}$ were used to mark the end of one burst and the beginning of the next burst; however, when two successive ISIs were $>0.5 \mathrm{sec}$, the middle spike was considered to be spurious and was discarded. All ISIs within a burst had values within the mean ISI \pm 2 SDs. We verified this method manually for $630 \mathrm{sec}$ of recorded data, and it was found to be highly accurate for detecting both spikes and bursts of spikes. At least eight burst cycles were detected and analyzed per experimental trial. For each experimental trial, cycle period, burst duration, duration of the inhibited phase, and final spike frequency at burst transition was calculated. Burst period was calculated as the time between the median spike of one burst and the median spike of the next burst. Determining the cycle period in this manner minimizes period variability because of spurious spikes at the beginning and end of a burst. Burst duration was calculated as the time between the first spike of the burst and the last spike of the burst. Duration of the inhibited phase was calculated as the time between the last spike of a burst and the first spike of the next burst. The final spike frequency was defined as the instantaneous spike frequency for the last two spikes of a burst. In experiments in which the maximal conductance of the h-current $\left(\bar{g}_{\mathrm{h}}\right)$ was varied directly in the silicon neuron or in the heart interneuron with dynamic clamp, we measured/calculated the activation variable $\left(m_{\mathrm{h}}\right)$ and determined the percentage of the inhibited phase at which it first reached its maximal value. For heart interneurons, even when $\bar{g}_{\mathrm{h}}$ was set to zero or a negative value in dynamic clamp, $m_{\mathrm{h}}$ of the h-current was calculated, and this point of maximal activation was determined to estimate when endogenous h-current would activate. Values reported here are the mean and SD across experiments, except as indicated. Statistical analysis was performed by using a one-way ANOVA and a multiple comparison of means using the Bonferroni $t$ test. A cutoff of $p=0.05$ was used to evaluate statistical significance. To simplify the presentation of the multiple comparisons, comparisons to a single chosen value of the varied parameter are indicated on the figures. The chosen value of the parameter for comparison was usually the minimum value, except when varying silicon neuron $(\mathrm{SiN}) \tau_{\mathrm{h}}$. Here, the value chosen was $0.5 \mathrm{sec}$ because some of the measured characteristics varied non-monotonically with $\operatorname{SiN} \tau_{\mathrm{h}}$, and with $\operatorname{SiN} \tau_{\mathrm{h}}$ set at $0.05 \mathrm{sec}$, these measured characteristics were at their minimum value.

\section{Results}

\section{Properties of the isolated silicon neuron}

Silicon neurons are real physical systems; they take voltages and currents as inputs and produce voltages and currents as outputs (Mahowald and Douglas, 1991; Patel and DeWeerth, 1997; Rasche and Douglas, 2000; Douglas and Rasche, 2002; Simoni et al., 2004). This approach differs from traditional mathematical modeling in that a model parameter value is represented by a voltage or current within the circuit, rather than an exact value in a numerical simulation. To assess the relationship between control voltages applied to the silicon neuron and the parameters of the emulated voltage-gated currents (Hodgkin-Huxley parameters), we measured the current-voltage relationships at the parameter inputs of the silicon neuron. These analyses produced data that a computer interface uses to translate Hodgkin-Huxley parameters to voltages that are applied to the circuit. Using this interface, we tuned the silicon neuron to the parameters derived from a mathematical oscillator heart interneuron model (Nadim et al., 1995; Hill et al., 2001). The time constants of activation and inactivation in the silicon neuron are fixed values and were set to the average values from the mathematical model (Table 1). With this set of parameters, the silicon neuron produced the desired tonic firing, but the action potentials were too wide $(15 \mathrm{msec})$ and the firing frequency was too high $(25 \mathrm{~Hz})$. We adjusted the halfmaximal activation and inactivation voltages and time constants of the fast currents to fix these discrepancies and to produce more realistic firing. This adjustment provided us with the canonical set of parameters that were used as a basis in all experiments (Table 1).

Differences between transistors can cause mismatches within the silicon neuron that can alter significantly the behavior of the 

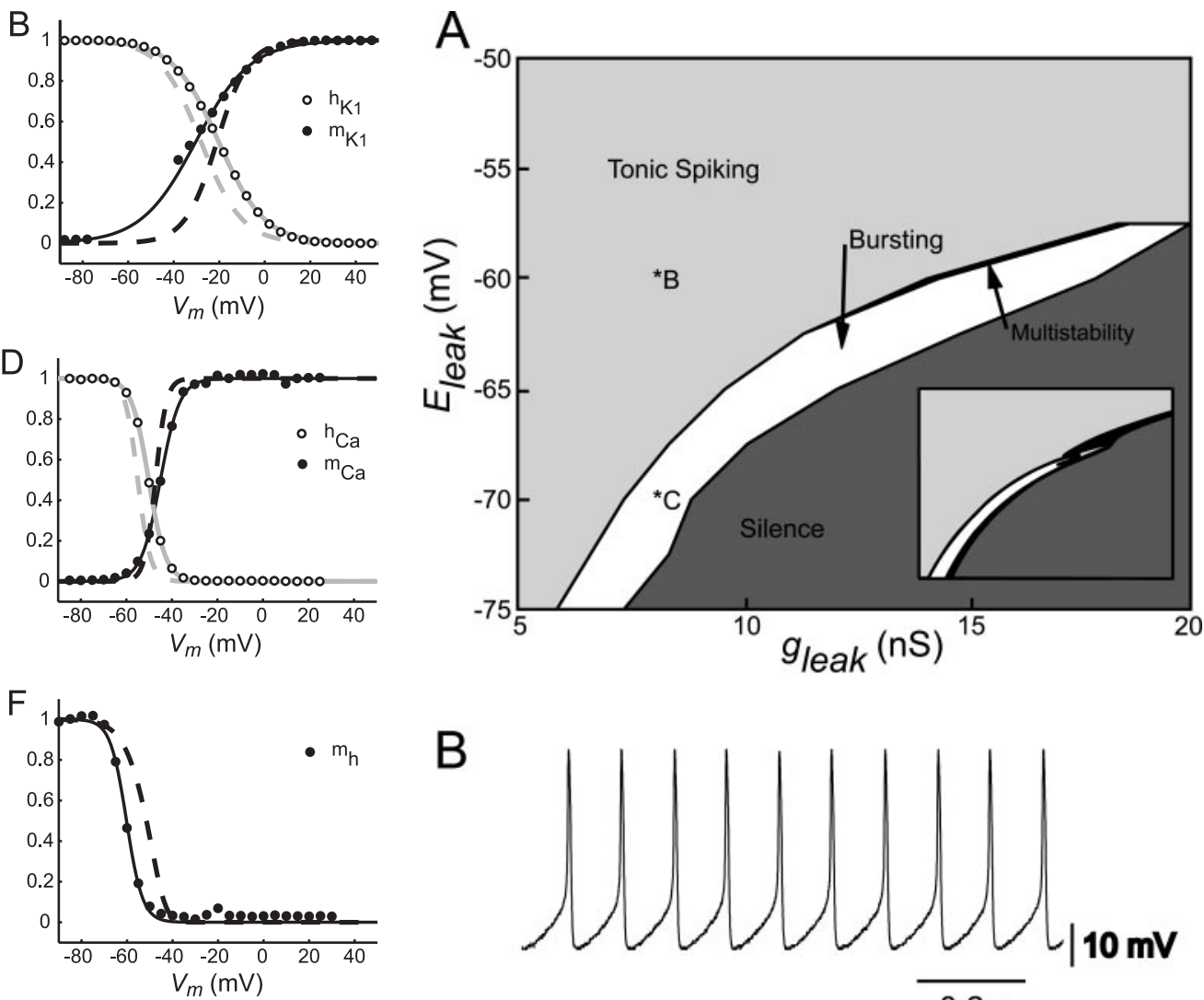
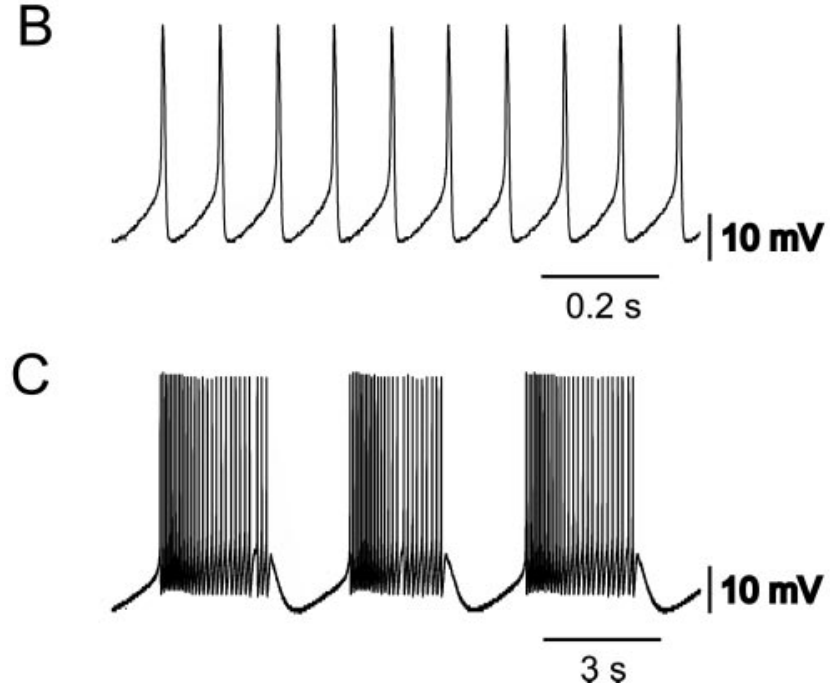

Figure 3. Activity of the silicon neuron depends on leak current parameters. $A$, Different types of activity, tonic spiking, bursting, and silence are expressed depending on the values of the leak reversal potential $\left(E_{\text {leak }}\right)$ and the leak conductance $\left(g_{\text {leak }}\right)$. The regions of silence and tonic spiking are separated by a region of intrinsic bursting. A small region, indicated in black (multistability), where bursting coexisted with tonic spiking was also observed. Inset, Similar activity map for the mathematical model of a heart interneuron (Cymbalyuk et al., 2002a). B, Typical activity of the silicon neuron when firing tonically. C, Typical activity of the silicon neuron when bursting intrinsically. Leak parameter values for the activity in $B$ and $C$ are indicated on the $\operatorname{map}$ in $A$.

Bifurcation analysis has proven to be an effective tool in analyzing transitions between different types of activity in heart interneurons (Cymbalyuk et al., 2002a). Activity in the mathematical model is sensitive to leak parameters $E_{\text {leak }}$ and $g_{\text {leak }}$ and produces bursting activity only in a narrow peninsula of this parameter space. This region of bursting in the parameter space $E_{\text {leak }}$ versus $g_{\text {leak }}$ separates areas of silence and tonic spiking (Fig. $3 A$, inset). To determine whether the silicon neuron behaves similarly to the mathematical model, we varied $E_{\text {leak }}(-75$ to $-50 \mathrm{mV}$ in steps of $2.5 \mathrm{mV})$ and $g_{\text {leak }}(5-20 \mathrm{nS}$ in steps of $1 \mathrm{nS})$ in the silicon neuron, and the resultant activity at each point was analyzed (Fig. 3A). As in the mathematical model, the silicon neuron displays bursting (Fig. $3 C$ ) in a narrow peninsula of these parameters that separates regions of silence and tonic firing (Fig. $3 B$ ). In
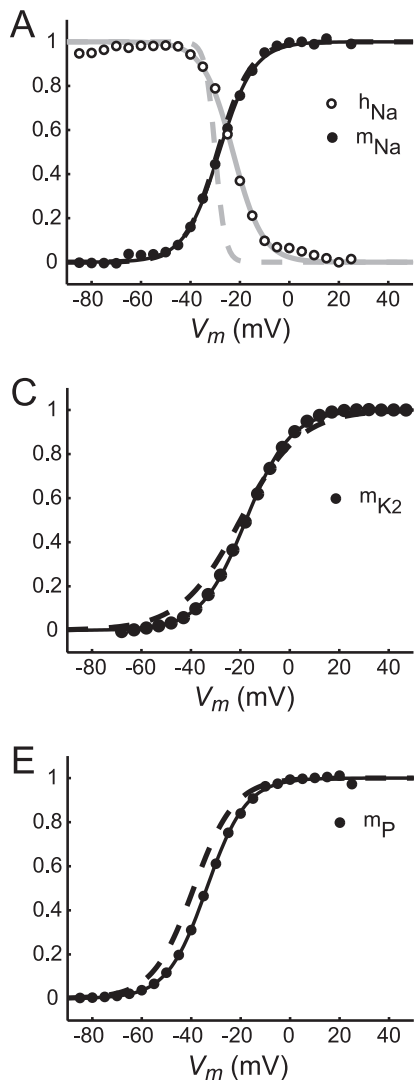

ters, the silicon neuron fired tonically with a spike frequency of $10-12 \mathrm{~Hz}$. represent data from voltage clamp. Solid lines denote best fit of data to the activation/inactivation equations of Hill et al. (2001). The dashed lines show steady-state activation and inactivation curves for the currents of the canonical mathematical heart interneuron model. $A$, Fast are not shown because of large conductance/low current artifact. $C$, Slow, non-inactivating potassium current $\left(I_{\mathrm{K} 2}\right)$. D, Slowly inactivating low-threshold calcium current $\left(I_{\mathrm{CaS}}\right)$. E, Persis-

circuit (Rasche et al., 1998; Patel and DeWeerth, 1999; Simoni et manufacturing process, and although circuit design techniques To assess the effects of transistor mismatch, we performed voltage-clamp analysis on the voltage-gated conductances of the steady-state activation of the fast sodium current $\left(m_{\infty \mathrm{Na}}\right)$ is nearly counterpart (Fig. 2A). This difference could explain the wide tively well matched, although there are both differences in slope and small offsets in the half-maximal voltages (Fig. $2 B$ ). $m_{\infty \mathrm{K} 2}$ $m_{\infty \mathrm{CaS}}, h_{\infty \mathrm{CaS}}, m_{\infty \mathrm{P}}$, and $m_{\infty \mathrm{h}}$ are all very similar to their mathematical model counterparts (Fig. $2 C-F$ ). The most noticeab and $I_{\mathrm{K} 1}$, particularly in the slopes of $h_{\infty \mathrm{Na}}$ and $m_{\infty \mathrm{K} 1}$. Unfortuints available for the silicon neuron, the slope of all steady-st activation and inactivation curves were set as a global parameter; adjusting the slope of these curves would adversely affect the well matched slope of the other curves. Using the canonical parame- 


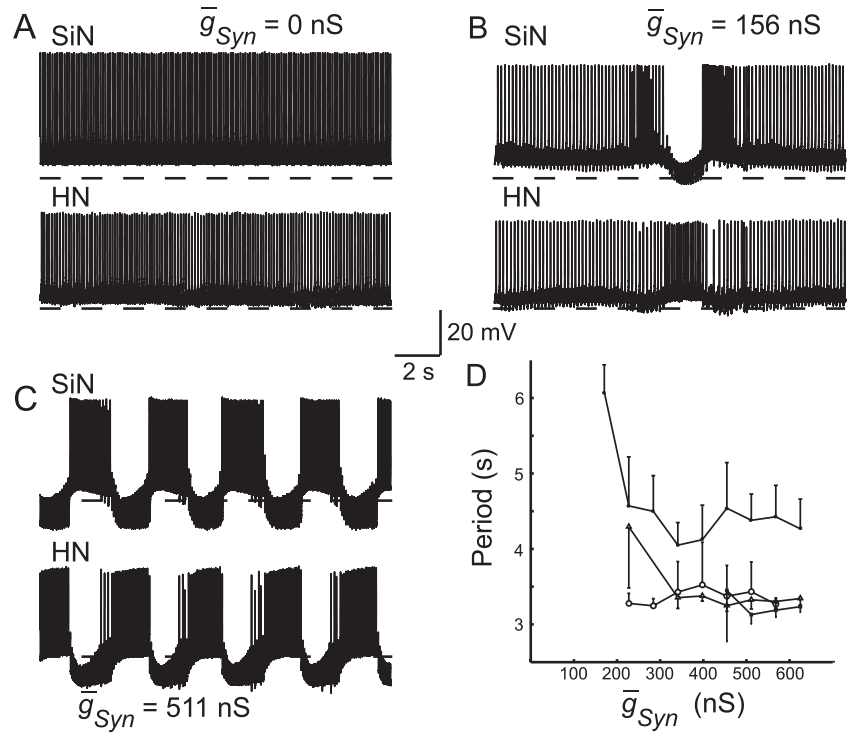

Figure 4. Dynamic-clamp-mediated inhibitory synapses of sufficient strength transform tonic firing into rhythmic antiphasic bursting in a hybrid half-center oscillator. $A$, Both the silicon neuron ( $\mathrm{SiN}$ ) and the pharmacologically isolated heart interneuron (HN) fire tonically in the absence of artificial synapses $\left(\bar{g}_{\text {syn }}=0 \mathrm{nS}\right)$. B, Weak artificial synapses ( $\operatorname{small} \bar{g}_{\text {syn }}$ ) result in sporadic lapses in activity but not rhythmic bursting. C, Strong artificial synapses (large $\bar{g}_{\text {Syn }}$ ) result in stable alternating rhythmic bursting. The dashed line in $A-C$ indicates $-50 \mathrm{mV}$. $D$, Results of four experiments in which $\bar{g}_{\text {Syn }}$ was varied between 0 and $625 \mathrm{nS}$. Different symbols represent different experiments. The period of rhythmic oscillations settle to a value that remains relatively unchanged with additional variations of $\bar{g}_{\text {Syn. }}$. The error bars indicate the SD of the period over $n \geq 8$ cycles for each trial of the four individual experiments.

addition, a narrow bistable region was found at the boundary between tonic firing and bursting, wherein the neuron could exhibit either tonic firing or rhythmic bursting, depending on the activity as the region was approached. Despite the differences in voltage-gated current parameters described before, these results are very similar to those from the mathematical model.

\section{Hybrid system: half-center oscillator}

Dynamic clamp was used to implement artificial synaptic conductances between the silicon neuron and an intracellularly recorded oscillator heart interneuron (Cymbalyuk et al., 2002b). We discovered after several trials that cell input resistance $\left(R_{\text {in }}\right)$ after sharp electrode penetration was critical to the success of establishing rhythmic bursting in the hybrid system. Poorly penetrated heart interneurons $\left(R_{\text {in }}<60 \mathrm{M} \Omega\right)$ fired at a high frequency and dominated the silicon neuron in the hybrid halfcenter. Moreover, the low resistance resulted in a fast membrane time constant and, therefore, poor synaptic integration. All results reported are from heart interneurons having $R_{\text {in }}>60 \mathrm{M} \Omega$. When pharmacologically isolated in bicuculline, the heart interneurons $\left(R_{\text {in }}>60 \mathrm{M} \Omega\right)$ fired tonically with an average frequency of $10.3 \pm 1.1 \mathrm{~Hz}$ ( $n=5$ trials) (Fig. $4 A$, bottom trace).

To determine appropriate synaptic strength for hybrid oscillations, the maximal synaptic conductance $\left(\bar{g}_{\text {Syn }}\right)$ for both artificial synapses was varied between 0 and $625 \mathrm{nS}$ in 12 equal steps for four separate preparations (Fig. 4). For low values of synaptic conductance, the two neurons continued to fire tonically, with occasional lapses in activity (Fig. $4 B$ ). Once sufficient synaptic strength had been reached, the neurons began alternating oscillations (Fig. 4C). Once stable oscillations were established, their period varied little with increasing $\bar{g}_{\text {Syn }}$ (Fig. $4 D$ ). The oscillations observed at $\bar{g}_{\text {Syn }}=511 \mathrm{nS}$ were regular; the coefficient of varia-

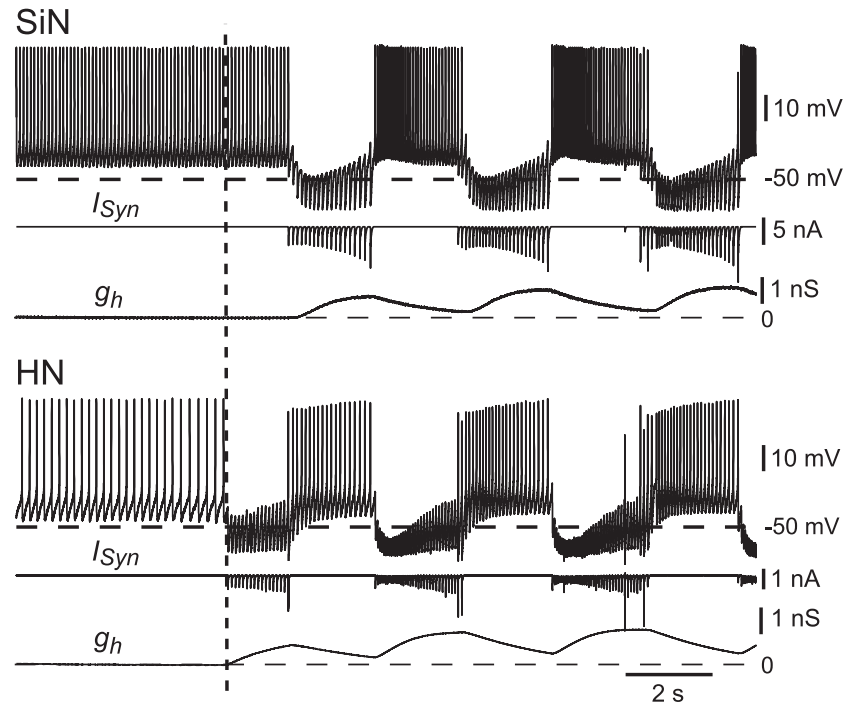

Figure 5. Strong artificial inhibitory synapses cause an immediate transition from tonic firing to rhythmic bursting in a hybrid half-center oscillator. Membrane potential, synaptic current $\left(I_{\text {Syn }}\right)$, and h-current conductance $\left(g_{h}\right)$ are shown for the silicon neuron (SiN) and the heart interneuron (HN). The vertical dashed line indicates the time at which the dynamic clamp was activated to enable the mutual inhibitory synapses. When one of the neurons is inhibited, its $I_{\mathrm{h}}$ activates, driving it back toward the firing threshold. Once it begins to fire, the other neuron is inhibited, its $I_{\mathrm{h}}$ activates, driving it back toward firing threshold so that it inhibits the first neuron, and the cycle repeats.

tion of the period ranged from 3.7 to $11.5 \%$ with a mean of $6.8 \%$ for the four preparations (Fig. 4D). We selected $500 \mathrm{nS}$ as the value of $\bar{g}_{\text {Syn }}$ for all additional experiments.

Using canonical parameters for the silicon neuron and with $\bar{g}_{\text {Syn }}$ set at $500 \mathrm{nS}$, rhythmic antiphasic bursting was obtained with all heart interneurons $\left(R_{\mathrm{in}}>60 \mathrm{M} \Omega\right)$. To initiate antiphasic bursting, the synapses were activated by moving their maximal conductances from 0 to the canonical operating value (Fig. 5). Activating the synapses caused one of the neurons to be inhibited while the other continued to fire tonically. Once a neuron was inhibited, its $I_{\mathrm{h}}$ was activated; meanwhile, the spike rate of the active neuron rapidly increased and then slowly decreased because of the activation and subsequent inactivation of $I_{\mathrm{CaS}}$. Once the spike rate in the active neuron was low enough, the inhibited neuron escaped from inhibition and began firing, inhibiting the other neuron. This process then repeated, resulting in antiphasic bursting.

The silicon neuron was thus suitable for investigating the role of intrinsic currents in the production and regulation of rhythmic bursting activity in a hybrid half-center oscillator. We chose to study $I_{\mathrm{h}}$ because it has been implicated as playing an important pacemaker function in a variety of systems (Luthi and McCormick, 1998). Our strategy was to vary $I_{\mathrm{h}}$ unilaterally in each member of the hybrid half-center oscillator.

\section{Unilateral variation of $\overline{\boldsymbol{g}}_{\mathrm{h}}$ in the silicon neuron}

To assess experimentally the effects of varying $\bar{g}_{\mathrm{h}}$ of the silicon neuron $\left(\operatorname{SiN} \bar{g}_{\mathrm{h}}\right)$, we established rhythmic antiphasic bursting between the silicon neuron and an isolated heart interneuron. In five separate experimental preparations, we varied $\operatorname{SiN} \bar{g}_{\mathrm{h}}$ from 0 to $8 \mathrm{nS}$ in increments of $2 \mathrm{nS}$ (canonical SiN $\bar{g}_{\mathrm{h}}=4 \mathrm{nS}$ ). At each interval, we assessed the cycle period, the burst duration, and the final spike frequency for each neuron. Typical activities at different values of $\operatorname{SiN} \bar{g}_{\mathrm{h}}$ are shown in Figure $6 \mathrm{~A}$.

With canonical parameter values, the cycle period was $4.7 \pm$ 
$0.4 \mathrm{sec}($ mean $\pm \mathrm{SD})$. This period is shorter than both the average period observed in the biological system and the period of the mathematical model $(8.8$ and $8.6 \mathrm{sec}$, respectively), although the period is close to the low end of the range observed in the biological system (6.4 sec) (Hill et al., 2001; Cymbalyuk et al., 2002a). There are several possible factors that might explain this difference. For example, sharp microelectrode penetration of the heart interneuron causes a decrease in the membrane time constant, reducing the efficacy of spike-mediated synaptic transmission. Limitations in the silicon neuron, such as the lack of voltage-dependent time constants, or in the dynamic-clamp synapses, such as the lack of graded synaptic transmission (Hill et al., 2001), could also play a role.

With increasing $\operatorname{SiN} \bar{g}_{\mathrm{h}}$, the oscillator cycle period decreased (Fig. 6A,B); there was a statistically significant effect of varying SiN $\bar{g}_{\mathrm{h}}$ on the period of the system (ANOVA) (Table 2). With complete removal of $I_{\mathrm{h}}\left(\operatorname{SiN} \bar{g}_{\mathrm{h}}=0\right)$, the silicon neuron was not always able to escape from inhibition $(n=2)$; in the cases in which it was able to escape $(n=3)$, the cycle period was greatly elongated $(13.3 \pm 1.8 \mathrm{sec})$. When SiN $\bar{g}_{\mathrm{h}}$ is varied, the change in the cycle period of the hybrid half-center oscillator is , mostly accounted for by the change in the duration of the inhibited phase of the silicon neuron (see Fig. 9D).

In this hybrid half-center oscillator, the duration of the inhibited phase of one cell is approximately equal to the burst duration of the opposing cell. With canonical parameters, the burst duration of the silicon neuron and the burst duration of the heart interneuron were similar $(2.5 \pm 0.5$ and $2.2 \pm 0.3 \mathrm{sec}$, respectively). With increasing $\operatorname{SiN} \bar{g}_{\mathrm{h}}$, the burst duration of the heart interneuron decreased, corresponding to a decrease in the inhibited phase of the silicon neuron (Fig. $6 A, C$ ). The final spike frequency of the heart interneuron also increased (Fig. 6A,D). There was a statistically significant effect of varying $\operatorname{SiN} \bar{g}_{\mathrm{h}}$ on the burst duration and final spike frequency of the heart interneuron but no apparent effect on these characteristics in the silicon neuron (ANOVA) (Table 2). The absence of a significant change in the burst duration of the silicon neuron indicates that variations in SiN $\bar{g}_{\mathrm{h}}$ selectively influence the inhibited phase of the oscillation. The increase in the final spike frequency of the heart interneuron indicates that with a higher $\bar{g}_{\mathrm{h}}$ the silicon neuron is able to overcome a higher frequency of inhibition from the heart interneuron and escape into its burst. Variations in $\operatorname{SiN} \bar{g}_{\mathrm{h}}$ change the balance of oscillations; with higher values of $\operatorname{SiN} \bar{g}_{h}$, the silicon neuron has a relatively longer burst duration (duty cycle), and with lower values of $\operatorname{SiN} \bar{g}_{\mathrm{h}}$, the heart interneuron has a relatively longer burst duration (duty cycle).

With canonical parameters, the final spike frequency is noticeably higher for the silicon neuron than for the heart interneuron; the heart interneuron is generally able to escape from a higher frequency of inhibition. This difference is most likely at- tributable to the difference in membrane time constants and input resistance, which determines the efficacy of dynamic-clamp synaptic currents in altering membrane potential.

At low values of $\operatorname{SiN} \bar{g}_{\mathrm{h}}$, the time point during the inhibited phase of the burst cycle at which $I_{\mathrm{h}}$ attained its maximal level of activation was well before the burst transition occurred (Fig. 6A). We expressed this time point as a percentage of the inhibited phase (see Fig. 9A-C). This observation indicates that the silicon neuron was "waiting" for a decrease in the inhibition it receives from the heart interneuron before it could begin firing. Therefore, the dynamics of spike frequency adaptation in the heart interneuron were determining the duration of the inhibited phase of the silicon neuron rather than the dynamics of $I_{\mathrm{h}}$ activation. As $\operatorname{SiN} \bar{g}_{\mathrm{h}}$ increased, $I_{\mathrm{h}}$ attained its maximal level of activation at relatively later and later time points in the inhibited phase. [The absolute amount of time necessary to attain maximal activation was nearly invariant, but this maximal activation occurred at a greater percentage of the inhibited phase (see Fig. 9A).] At high values of $\operatorname{SiN} \bar{g}_{\mathrm{h}}, I_{\mathrm{h}}$ attained its maximal level of activation practically at the end of the inhibited phase (Fig. 6A). This observation indicates that at high values of $\operatorname{SiN} \bar{g}_{\mathrm{h}}$ the dynamics of $I_{\mathrm{h}}$ activation were determining the duration of the inhibited phase of the silicon neuron rather than the dynamics of spike frequency adaptation in the heart interneuron. 
Table 2. One-way ANOVA ( $p$ values)

\begin{tabular}{|c|c|c|c|c|c|c|}
\hline Experiment & $\begin{array}{l}\text { Varied neuron } \\
\text { period }\end{array}$ & $\begin{array}{l}\text { Unvaried neuron } \\
\text { period }\end{array}$ & $\begin{array}{l}\text { Varied neuron } \\
\text { burst duration }\end{array}$ & $\begin{array}{l}\text { Unvaried neuron } \\
\text { burst duration }\end{array}$ & $\begin{array}{l}\text { Varied neuron final } \\
\text { spike frequency }\end{array}$ & $\begin{array}{l}\text { Unvaried neuron } \\
\text { final spike frequency }\end{array}$ \\
\hline $\bar{g}_{\mathrm{h}} \mathrm{SiN}$ & 0.003 & 0.002 & 0.995 & $2.4 e-6$ & 0.997 & 0.027 \\
\hline $\bar{g}_{\mathrm{h}} \mathrm{HN}$ & 0.029 & 0.030 & 0.474 & 0.006 & 0.973 & 0.080 \\
\hline $\bar{g}_{\mathrm{h}} \mathrm{HN}(\mathrm{w} / \mathrm{Cs})$ & 9.7e-9 & $9.7 e-9$ & 0.180 & $1.53 e-10$ & 0.949 & $8.7 e-4$ \\
\hline$\tau_{\mathrm{h}} \mathrm{SiN}$ & 0.003 & 0.002 & $3 e-7$ & 0.068 & 0.828 & 0.170 \\
\hline
\end{tabular}

Values in bold indicate statistical significance.

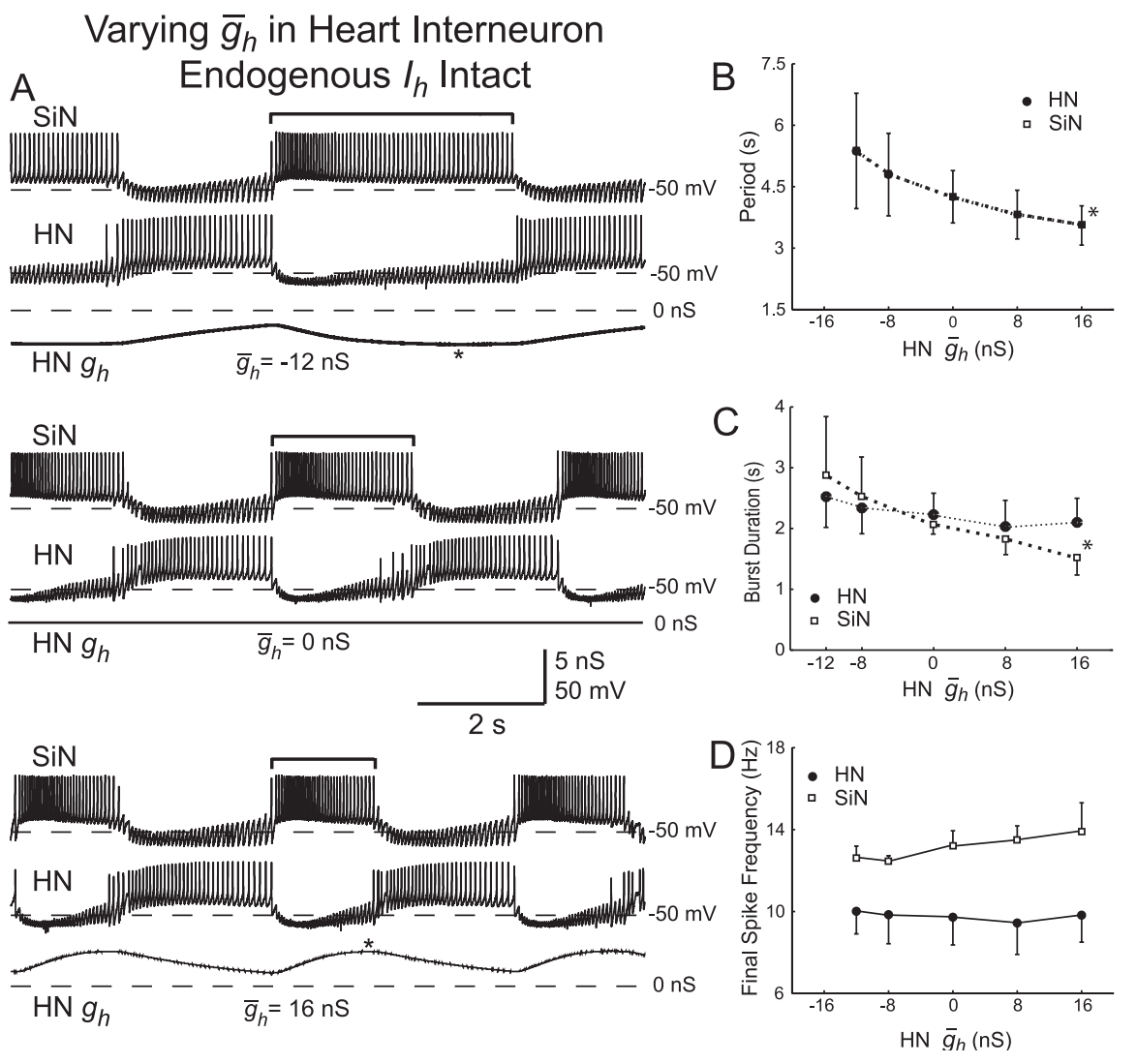

Figure 7. Variation of $\bar{g}_{\mathrm{h}}$ in the heart interneuron $\left(\operatorname{SiN} \bar{g}_{\mathrm{h}}\right)$ of a hybrid half-center oscillator with endogenous $I_{\mathrm{h}}$ present. $A$, Typical activity at three different values of $\mathrm{HN} \bar{g}_{\mathrm{h}}$. Voltage traces for the silicon neuron (SiN) and the heart interneuron (HN) and h-current conductance $\left(\mathrm{HN} g_{\mathrm{h}}\right)$ for the heart interneuron are shown. As $\mathrm{HN} \bar{g}_{\mathrm{h}}$ increases, the burst duration (indicated by brackets) of the unaltered silicon neuron decreases. The asterisks indicate when during the inhibited phase h-current first reaches its maximal level of activation. $B$, Increasing $H N \bar{g}_{\mathrm{h}}$ decreases the oscillator period. The period of the silicon neuron and the heart interneuron are the same. $C$, Increasing $H N \bar{g}_{\mathrm{h}}$ decreases burst duration of the silicon neuron, which is equivalent to the duration of the inhibited phase of the heart interneuron. $D$, Increasing $H N \bar{g}_{\mathrm{h}}$ increases the final spike frequency of the silicon neuron, whereas the final spike frequency of the heart interneuron is relatively constant. In $B-D$, a thick line connecting data points indicates a significant effect of varying $\mathrm{HN} \bar{g}_{\mathrm{h}}$ as determined by ANOVA $(p<0.05)$, and asterisks indicate a significant difference $(p<0.05)$ between the measured value and the corresponding value when $\mathrm{HN} \bar{g}_{\mathrm{h}}$ was at its smallest value $(-12 \mathrm{nS})$ in pairwise comparisons.

\section{Unilateral variation of $\bar{g}_{\mathrm{h}}$ in the heart interneuron}

To vary the strength of $I_{\mathrm{h}}$ in the heart interneuron, we used dynamic clamp to create a model $I_{\mathrm{h}}$, which could be used in conjunction with the endogenous $I_{\mathrm{h}}$ of the heart interneuron. By setting the maximal conductance of the dynamic clamp $I_{\mathrm{h}}$, heart interneuron (HN) $\bar{g}_{\mathrm{h}}$, to be greater than zero, we added to the endogenous $I_{\mathrm{h}}$. We subtracted from the endogenous $I_{\mathrm{h}}$ by setting $\mathrm{HN} \bar{g}_{\mathrm{h}}$ to negative values. Subtracting $I_{\mathrm{h}}$ in excess of the effective endogenous $I_{\mathrm{h}}$ created a positive feedback system, driving the cell to an extremely hyperpolarized state. Several cells were tested, and it was found that an artificial maximal conductance of -16 $\mathrm{nS}$ would almost always cause this undesirable condition to occur, but $-12 \mathrm{nS}$ would not; $-12 \mathrm{nS}$ was therefore chosen as the maximal "negative conductance." Furthermore, the heart interneuron required a larger variation in $I_{\mathrm{h}}$ than did the silicon neuron to observe similar effects, so $\mathrm{HN} \bar{g}_{\mathrm{h}}$ was varied over a larger range than in the case for the silicon neuron.

In five experiments, hybrid oscillations were established, and $\mathrm{HN} \bar{g}_{\mathrm{h}}$ was varied between -12 and $+16 \mathrm{nS}$. SiN $\bar{g}_{\mathrm{h}}$ was kept constant at the canonical value of $4 \mathrm{nS}$. Typical activity for different levels of $\mathrm{HN}$ $\bar{g}_{\mathrm{h}}$ is shown in Figure $7 \mathrm{~A}$. With no addition or subtraction to the endogenous $I_{\mathrm{h}}$ (HN $\bar{g}_{\mathrm{h}}=0 \mathrm{nS}$ ), the cycle period of the hybrid oscillator was $4.24 \pm 0.6 \mathrm{sec}$, and the burst duration of the silicon neuron $(2.1 \pm 0.3$ $\mathrm{sec})$ was similar to the burst duration of the heart interneuron $(2.2 \pm 0.4 \mathrm{sec})$. With increasing $\mathrm{HN} \bar{g}_{\mathrm{h}}$, the period of the system decreased (Fig. 7A,B); there was a statistically significant effect of varying $\mathrm{HN} \bar{g}_{\mathrm{h}}$ on period (ANOVA) (Table 2). Moreover, with increasing $\mathrm{HN} \bar{g}_{\mathrm{h}}$, the burst duration of the silicon neuron decreased, corresponding to a decrease in the inhibited phase of the heart interneuron, and the final spike frequency of the silicon neuron increased (Fig. $7 A, C, D$ ). There was a statistically significant effect of varying $\mathrm{HN} \bar{g}_{\mathrm{h}}$ on the burst duration of the silicon neuron, but the effect on final spike frequency of the silicon neuron was not statistically significant ( $p=0.08$; ANOVA) (Table 2). There was no apparent effect of varying $\mathrm{HN} \bar{g}_{\mathrm{h}}$ on burst duration or final spike frequency in the heart interneuron (ANOVA) (Table 2).

As observed when varying $\operatorname{SiN} \bar{g}_{\mathrm{h}}$, the change in period when varying $\mathrm{HN} \bar{g}_{\mathrm{h}}$ was attributable to a change in the duration of the inhibited phase of the modified neuron (Fig. 9D). The duration of the inhibited phase of the heart interneuron, which is equivalent to the burst duration of the silicon neuron, decreased, whereas the burst duration of the heart interneuron remained relatively constant. These results are remarkably similar to the case when $\operatorname{SiN} \bar{g}_{\mathrm{h}}$, was varied; increasing $\mathrm{HN} \bar{g}_{\mathrm{h}}$ caused $I_{\mathrm{h}}$ to attain its maximal level of activation at a relatively later point of the inactive phase of the burst cycle (Fig. $9 B)$. Although the effect here is not as striking as in the $\operatorname{SiN} \bar{g}_{\mathrm{h}}$ case, it is still apparent.

In six additional experiments, we blocked the endogenous $I_{\mathrm{h}}$ of the heart interneuron with $2 \mathrm{mM} \mathrm{Cs}^{+}$, and the dynamic clamp was then used to reintroduce a completely artificial $I_{\mathrm{h}}$ into the 
heart interneuron. $\mathrm{HN} \bar{g}_{\mathrm{h}}$ was then varied from 0 to $32 \mathrm{nS}$ in $8 \mathrm{nS}$ increments. Typical activity for different levels of $\mathrm{HN} \bar{g}_{\mathrm{h}}$ is shown in Figure $8 \mathrm{~A}$. As observed in the other experiments in which $\bar{g}_{\mathrm{h}}$ was varied, increasing $\mathrm{HN} \bar{g}_{\mathrm{h}}$ decreased the cycle period of the system (Fig. $7 A, B$ ); there was a statistically significant effect of varying HN $\bar{g}_{\mathrm{h}}$ on the period (ANOVA) (Table 2). Moreover, with increasing $\mathrm{HN} \bar{g}_{\mathrm{h}}$, the burst duration of the silicon neuron decreased, corresponding to a decrease in the inhibited phase of the heart interneuron, and the final spike frequency of the silicon neuron increased (Fig. $7 A, C, D$ ). There was a statistically significant effect of varying $\mathrm{HN} \bar{g}_{\mathrm{h}}$ on the burst duration and final spike frequency of the silicon neuron but no apparent effect on these characteristics in the heart interneuron (ANOVA) (Table 2). As in the previous experiments, the change in period was attributable to a change in the duration of the inhibited phase of the modified neuron (Fig. 9D). Increasing $\mathrm{HN} \bar{g}_{\mathrm{h}}$ also led to an increase in the percentage of the inhibited phase at which $I_{\mathrm{h}}$ attained its maximal level of activation in the heart interneuron (Figs. 8A, 9C), which was very similar to when $\bar{g}_{\mathrm{h}}$ was varied in the silicon neuron.

The remarkable similarity in results when $\bar{g}_{\mathrm{h}}$ was varied in the silicon neuron and the living heart interneuron, both with endogenous $I_{\mathrm{h}}$ present and when it was blocked by $\mathrm{Cs}^{+}$, demonstrates that the dynamics of dynamic clamp $I_{\mathrm{h}}$ are compatible with the intrinsic currents in the living neuron and that $I_{\mathrm{h}}$ serves a similar function in the heart interneuron and in the model neuron.

\section{Unilateral variation of $I_{h}$ in mathematical model of a half-center oscillator}

To corroborate our results from the hybrid systems analysis, we investigated the effects of unilateral variation in a mathematical model of a leech heartbeat half-center oscillator (Hill et al., 2001). Previous modeling studies indicated that $\bar{g}_{\mathrm{h}}$ determines the final spike frequency, the firing frequency at which a heart interneuron escapes the inhibition of the other neuron in the half-center oscillator (Hill et al., 2001). However, these studies investigated only the effects of bilateral variation of parameters, not the unilateral variations that we used in our hybrid systems analysis. Using the GENESIS neural simulation environment, we varied $\bar{g}_{\mathrm{h}}$ of one model neuron of a model half-center oscillator from 0 to 8 $\mathrm{nS}(4 \mathrm{nS}$ canonical) in $0.5 \mathrm{nS}$ increments. We then assessed the resultant activity for cycle period, burst duration, duration of the inhibited phase, and final spike frequency.

Unilateral variation of $\bar{g}_{\mathrm{h}}$ in the model revealed effects similar to those observed in the hybrid system (Fig. 10). Increasing $\bar{g}_{\mathrm{h}}$ unilaterally resulted in a decrease in the burst duration of the unmodified (constant) model cell corresponding to a decrease in the duration of the inactive phase of the modified model neuron (Fig. 10B). The burst duration of the modified model neuron, however, exhibited virtually no change. This selectivity for influ- encing the inactive phase of the burst was not apparent when $\bar{g}_{\mathrm{h}}$ was varied bilaterally (Fig. $10 \mathrm{~B}$, inset). Final spike frequency increased nearly linearly for the constant model neuron but remained constant for the varied model neuron (Fig. 10C). The changes in final spike frequency in the unmodified model neuron for unilateral variation of $\bar{g}_{\mathrm{h}}$ corresponded closely to the changes in final spike frequency observed for symmetric variation of $\bar{g}_{\mathrm{h}}$ (Fig. 10C, inset). These modeling results for asymmetric variation of $\bar{g}_{\mathrm{h}}$ further support the hypothesis developed from symmetric variation of $\bar{g}_{\mathrm{h}}$ in the model (Hill et al., 2001) and from our hybrid system analysis that $\bar{g}_{\mathrm{h}}$ sets the final spike frequency from which an inhibited neuron escapes.

Finally, the changes in cycle period of the model half-center oscillator observed under bilateral and unilateral variation of $\bar{g}_{\mathrm{h}}$ are qualitatively very similar (data not shown). Essentially, the change in period for a bilateral change in $\bar{g}_{\mathrm{h}}$ is double that for a unilateral change in $\bar{g}_{\mathrm{h}}$.

\section{Unilateral variation of $\tau_{\mathrm{h}}$ in the silicon neuron.}

We assessed the effect of varying $\tau_{\mathrm{h}}$ (the time constant of activation and deactivation of $I_{\mathrm{h}}$ ) on the rhythmic activity of the hybrid oscillator only by varying this parameter in the silicon neuron, having demonstrated that alterations of the properties of the silicon neuron can describe similar changes in the heart interneuron. 

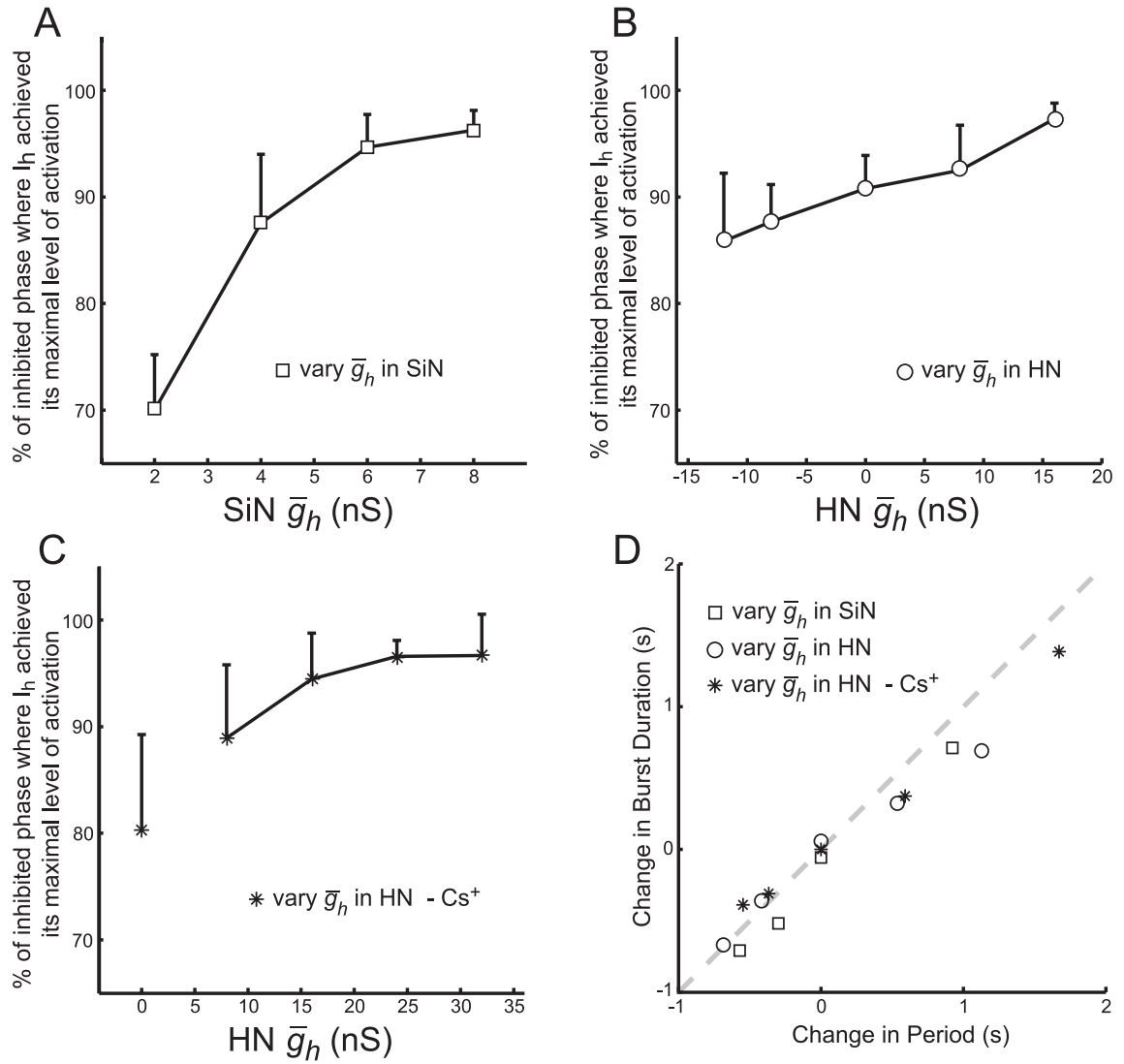

Figure 9. $A-C, \bar{g}_{\mathrm{h}}$ determines when $I_{\mathrm{h}}$ reaches its maximal level of activation during the inhibited phase of the burst cycle of a hybrid half-center oscillator. We measured this timing as the percentage of the inhibited phase at which $I_{\mathrm{h}}$ achieved its maximal level of activation. $A, \operatorname{SiN} \bar{g}_{\mathrm{h}}$ varied. $B, \mathrm{HN} \bar{g}_{\mathrm{h}}$ varied in the presence of endogenous $I_{\mathrm{h}} . C, \mathrm{HN} \bar{g}_{\mathrm{h}}$ varied with endogenous $I_{\mathrm{h}}$ blocked by $2 \mathrm{~mm} \mathrm{Cs}{ }^{+}$. The data point at $\mathrm{HN} \bar{g}_{\mathrm{h}}=0 \mathrm{nS}$ is rather fanciful because there is no endogenous $\mathrm{h}$-current and none is added or subtracted with dynamic clamp. Thus, this point is not connected to the rest by a line segment. D, Changes in the oscillator period caused by variation of $\bar{g}_{\mathrm{h}}$ are primarily attributable to changes in burst duration of the non-modified "neuron" (equivalent to duration of the inactive phase in the modified neuron). The change in burst duration from the canonical operating point for the non-modified neuron is plotted versus the change in the oscillator period. The dashed line indicates that all of the change in the oscillator period is attributable to change in the burst duration of the non-modified neuron. The data points all lie near this line, indicating that $I_{\mathrm{h}}$ is selectively acting to shorten the inhibited phase of the burst cycle of the oscillator.

In seven experiments, we varied $\tau_{\mathrm{h}}$ of the silicon neuron ( $\mathrm{SiN}$ $\tau_{\mathrm{h}}$ ) from 0.25 to $8 \mathrm{sec}$ (canonical $\tau_{\mathrm{h}}=2 \mathrm{sec}$ ). Typical activity at different values of $\operatorname{SiN} \tau_{\mathrm{h}}$ is shown in Figure $11 \mathrm{~A}$. With canonical parameter values, the oscillator cycle period was $4.19 \pm 0.42 \mathrm{sec}$, and the burst duration of the silicon neuron $(1.9 \pm 0.1 \mathrm{sec})$ and the heart interneuron were similar $(2.1 \pm 0.4 \mathrm{sec})$ (Fig. 11A). Alterations of $\operatorname{SiN} \tau_{\mathrm{h}}$ had no statistically significant effect of the final spike frequency for either cell (Fig. 11D) (ANOVA) (Table 2 ). There was a statistically significant effect of varying $\operatorname{SiN} \tau_{\mathrm{h}}$ on the period of the system (ANOVA) (Table 2), but this effect was complex (Fig. 11A). Between 0.5 and $8 \mathrm{sec}$, increases in $\mathrm{SiN} \tau_{\mathrm{h}}$ led to increases in period, but below $0.5 \mathrm{sec}$ period decreased with increasing $\tau_{\mathrm{h}}$, although pairwise comparisons showed that this increase did not quite reach significance between $\operatorname{SiN} \tau_{\mathrm{h}}=0.5$ and $0.25 \mathrm{sec}(p=0.06)$. There was also no statistically significant effect of varying $\mathrm{SiN} \tau_{\mathrm{h}}$ on burst duration of the unvaried heart interneuron ( $p=0.07$ ) (ANOVA) (Table 2), although a trend in the data similar to the effect on period is apparent (Fig. 11C). Surprisingly, there was a very small, but statistically significant, effect of $\operatorname{SiN} \tau_{\mathrm{h}}$ on the burst duration of the silicon neuron (ANOVA) (Table 2; Fig. 11C); this effect reflects the slow deactivation of $I_{\mathrm{h}}$ during the burst, especially when $\operatorname{SiN} \tau_{\mathrm{h}}$ is large, that prolongs the burst. Decreasing $\mathrm{SiN} \tau_{\mathrm{h}}$ below the canonical value also led to a decrease in the percentage of the inhibited phase at which $I_{\mathrm{h}}$ attained its maximal level of activation in the heart interneuron, but no effect was noted with increases of $\operatorname{SiN} \tau_{\mathrm{h}}$ above the canonical value (Fig. 11A) (group data not shown).

The increase in oscillator period for low values of $\tau_{\mathrm{h}}$, seen as a trend in the data of Figure $11 C$, was seen as a qualitatively similar effect in the mathematical model. As $\tau_{\mathrm{h}}$ decreases, $I_{\mathrm{h}}$ activates faster. Up to a certain point, this means that the depolarizing current will be present at an earlier time during the inhibited phase of the burst. The duration of the inhibited phase will be shortened, and the period of oscillations will decrease. As $\tau_{\mathrm{h}}$ decreases beyond a certain level, however, the activation level of $I_{\mathrm{h}}$ begins to approximate its steady-state value. The depolarizing effects of $I_{\mathrm{h}}$ move the membrane potential to a level at which $I_{\mathrm{h}}$ deactivates before the neuron reaches threshold. Thus, very little depolarizing current will be available to drive the neuron out of inhibition, and the duration of the inhibited phase will therefore increase.

\section{Discussion}

We have constructed a hybrid half-center oscillator using a living heart interneuron from the medicinal leech and a silicon model neuron. Using this hybrid halfcenter oscillator, we investigated the role of the hyperpolarization-activated inward current $I_{\mathrm{h}}$ in rhythm generation and the control of period and burst duration. We varied three parameters of $I_{\mathrm{h}}$ in the silicon neuron: $\bar{g}_{\mathrm{h}}$ (the maximal conductance of $I_{\mathrm{h}}$ ) and $\tau_{\mathrm{h}}$ (the time constant of $I_{\mathrm{h}}$ activation/deactivation). Using dynamic clamp, we also varied $\bar{g}_{\mathrm{h}}$ in the heart interneuron, both with endogenous $I_{\mathrm{h}}$ present and with endogenous $I_{\mathrm{h}}$ blocked, thereby demonstrating that the heart interneuron and the silicon neuron were functionally similar. Increasing $\bar{g}_{\mathrm{h}}$ increased the firing frequency of the active (unvaried) neuron at which the inhibited (varied) neuron escaped from inhibition. As a result, increasing $\bar{g}_{\mathrm{h}}$ decreased the duration of the inhibited phase in the varied neuron and decreased the cycle period. Varying $\tau_{\mathrm{h}}$ had no effect on the spike frequency at transition; as it decreased, however, the cycle period of the hybrid oscillator initially decreased but then increased.

\section{Validity of the hybrid neuronal network}

For several years, numerous efforts have been made to construct hybrid networks for neuronal network investigations. The goal of such investigations has been to use the controllability and well defined structure of a model to better understand neuronal function, while still retaining the realism provided by living neurons. In general, these efforts have taken two different approaches. The first approach has used nonphysiological models, such as nonlinear oscillators or phenomenological model neurons, coupled with a neuron or a neuronal network (Yarom, 1991; Szucs et al., 2000). The relative simplicity of these models facilitates the study of dynamical proper- 
ties; such study is extremely difficult with more complicated models. The second approach has been to use physiologically realistic, conductance-based model neurons. This approach facilitates the investigation of both the mechanisms by which activity is produced and the functional role of different conductances (Renaud-LeMasson et al., 1993; Le Masson et al., 1995, 2002; Nadim and Manor, 2001; Manor and Nadim, 2001; Derjean et al., 2003).

Our hybrid system used an analog silicon neuron that implemented a realistic conductance-based model based on the Hodgkin-Huxley formalism (Hodgkin and Huxley, 1952; Simoni et al., 2004). This mechanistic approach to modeling was necessary because we were interested in studying how intrinsic ionic currents contribute to generating rhythmic oscillatory activity. Whereas this goal could have been accomplished with a more common digital model, the silicon neuron provides several advantages in terms of scalability and power consumption that will be important in expanding the scale of the model in future hybrid systems. Although there are often many difficulties in working with silicon neurons, great care was taken to ensure that the properties of our silicon neuron were closely matched to those of the heart interneuron. Voltageclamp analysis performed on the silicon neuron revealed that its intrinsic currents are well matched to those of a mathematical model of a heart interneuron. As a result, when the tonically firing model neuron and tonically firing biological neuron were coupled with inhibitory synapses using dynamic clamp, they produced alternating rhythmic bursting. This transformation in activity is analogous to results observed when inhibitory synaptic transmission is reversibly blocked in heart interneurons recorded by sharp microelectrode penetration (Schmidt and Calabrese, 1992; Cymbalyuk et al., 2002a).

The oscillations produced by our hybrid system were very similar to those observed in the living heart interneuron halfcenter oscillator. Furthermore, we demonstrated that qualitatively similar changes in cycle period, burst duration, and final spike frequency were observed when $\bar{g}_{\mathrm{h}}$ was varied either in the silicon neuron or in the heart interneuron. This demonstration of symmetry in observed effects between the model neuron and a heart interneuron indicates that conclusions drawn from the model can be applied confidently to the living system.

\section{Role of $I_{\mathrm{h}}$ in heart interneuron half-center oscillators}

$I_{\mathrm{h}}$ has been implicated in the generation of rhythmic activity in numerous vertebrate and invertebrate systems (Pape, 1996; Sharp et al., 1996; Luthi and McCormick, 1998; Robinson and Siegelbaum, 2003). In the thalamus, for example, the interaction of $I_{\mathrm{h}}$ with a low-threshold $\mathrm{Ca}^{2+}$ current leads to the generation of oscillatory bursting activity that plays an important role in sleep (McCormick and Huguenard, 1992). Additionally, it has been shown that $I_{\mathrm{h}}$ can influence or pace rhythmic activity within the inferior olive, the hippocampus, and the pre-Botzinger complex of the mammalian brain (Maccaferri and McBain, 1996; Bal and McCormick, 1997; Thoby-Brisson et al., 2000). Given the widespread distribution of $I_{\mathrm{h}}$ and its importance in the generation of rhythmic activity, it is not surprising that $I_{\mathrm{h}}$ appears to be a frequent target of modulation (Kiehn and Harris-Warrick, 1992; Harris-Warrick et al., 1995, Wang et al., 2002).

Previous modeling and physiological studies in our laboratory indicate that $I_{\mathrm{h}}$ exerts an important control on period in heart interneuron half-center oscillators (Olsen and Calabrese, 1996; Hill et al., 2001). By making unilateral changes in this analysis, we have supplemented the previous work to demonstrate the selectivity of $I_{\mathrm{h}}$ in controlling the inhibited phase of the heart interneuron burst cycle. In both the mathematical model and the hybrid system, modulation of $I_{\mathrm{h}}$ by $\bar{g}_{\mathrm{h}}$ and $\tau_{\mathrm{h}}$ substantially affect the duration of the inhibited phase of the oscillation, with little or no effect on burst duration of the varied neuron. Thus, in addition to its role as a period regulator, $I_{\mathrm{h}}$ can also alter the balance of activity (duty cycle) in a half-center oscillator. Our results are consistent with other investigations into the functional role of $I_{\mathrm{h}}$, which demonstrated that increasing $I_{\mathrm{h}}$ decreases cycle period and increases the duty cycle of affected cell (MacLean et al., 2003; Zhang et al., 2003). Because leech heartbeat half-center oscillators always produce equally balanced rhythmic oscillations, any modulatory process that acts on $\bar{g}_{\mathrm{h}}$ or $\tau_{\mathrm{h}}$ would have to either act bilaterally or additionally effect some other property to maintain an appropriate balance of activity.

Overall, the results produced by experiments with the hybrid system were very similar to the results observed in simulated 
Varying $\tau_{h}$ in Silicon Interneuron
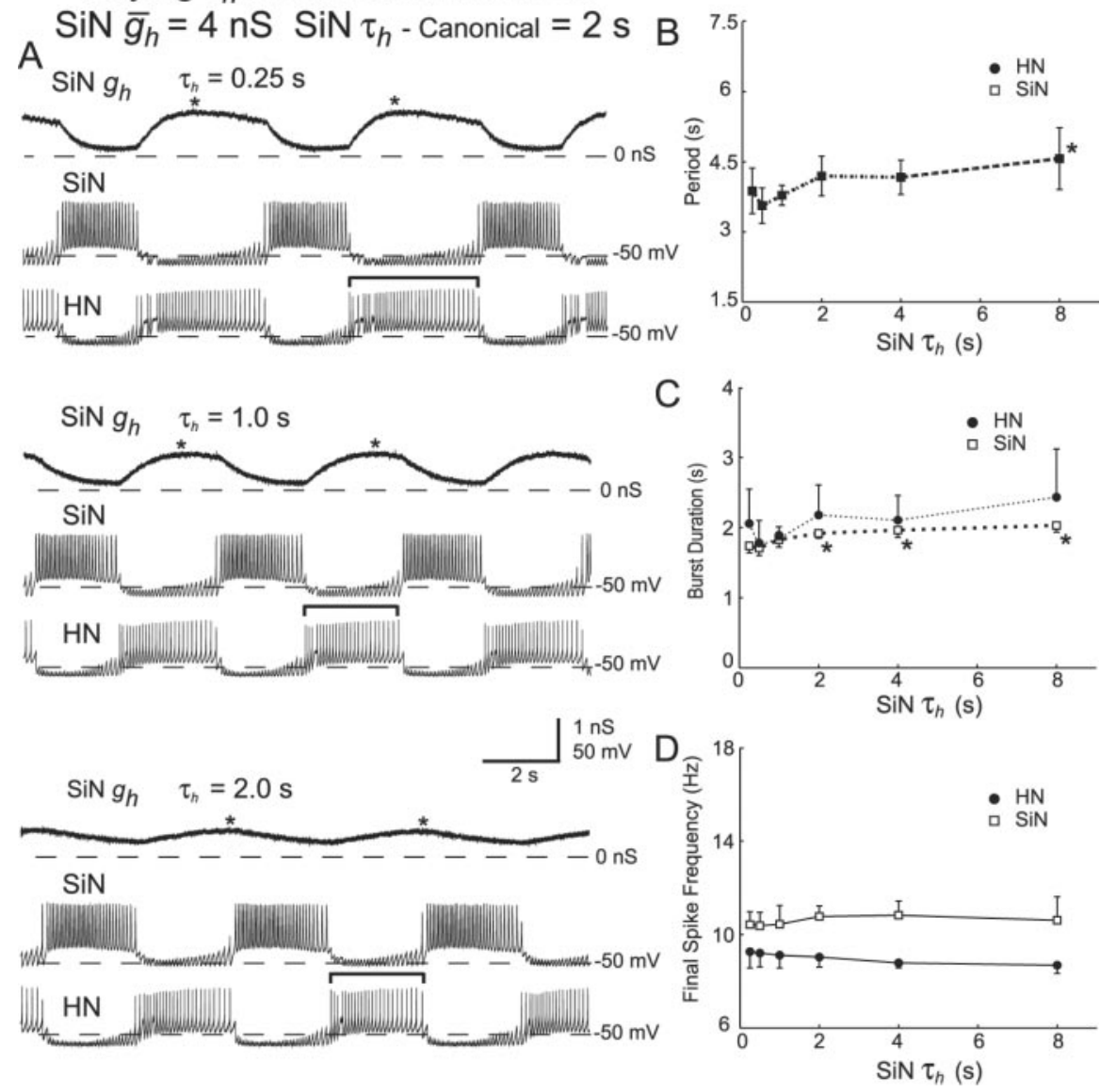

Figure 11. Variation of $\tau_{\mathrm{h}}$ in the silicon neuron $\left(\mathrm{SiN} \tau_{\mathrm{h}}\right.$ ) of a hybrid half-center oscillator. $A$, Typical activity at three different values of $\mathrm{HN} \bar{g}_{\mathrm{h}}$. Voltage traces for the silicon neuron (SiN) and the heart interneuron (HN) and h-current conductance $\left(\operatorname{SiN} g_{\mathrm{h}}\right)$ for the heart interneuron are shown. The burst duration of the unaltered heart interneuron is indicated by brackets. $B$, Variations in $\operatorname{SiN} \tau_{h}$ have a significant effect on the cycle period. Decreasing $\operatorname{SiN} \tau_{h}$, down to $0.5 \mathrm{sec}$, causes a decrease in the cycle period. An additional decrease in $\mathrm{SiN} \tau_{\mathrm{h}}$, however, causes an increase in the cycle period. C, Decreasing $\operatorname{SiN} \tau_{\mathrm{h}}$ decreases the burst duration of the heart interneuron and also causes a slight decrease in the burst duration of the silicon neuron. $D$, Variations in $\operatorname{SiN} \tau_{\mathrm{h}}$ have no significant effect on the final spike frequency of either the silicon neuron or the heart interneuron. In $B-D$, a thick line connecting data points indicates a significant effect of varying $\operatorname{SiN} \tau_{\mathrm{h}}$ as determined by ANOVA $(p<0.05)$, and asterisks indicate a significant difference ( $p<0.05$ ) between the measured value and the corresponding value when $\operatorname{SiN} \tau_{\mathrm{h}}$ was set at 0.5 sec in pairwise comparisons.

experiments with the mathematical model. There was, however, one prominent difference that provides some insight into the role of $I_{\mathrm{h}}$ in heart interneuron half-center oscillators. The hybrid system oscillates at a substantially shorter period than the mathematical model, although the average period of the hybrid system is close to the lower limit of periods observed in the biological oscillator (Cymbalyuk et al., 2002a). Despite this difference, the qualitative effects of $\bar{g}_{\mathrm{h}}$ and $\tau_{\mathrm{h}}$ on period, burst duration, and final spike frequency are the same in both the hybrid system and in the mathematical model. This result not only demonstrates the validity of the hybrid system but also reveals that the qualitative effects of $\bar{g}_{\mathrm{h}}$ and $\tau_{\mathrm{h}}$ variation are apparently independent of the cycle period. Modulatory mechanisms are often dependent on the state of the neuron (Goldman et al., 2001). Identifying mechanisms that are state independent is important because they provide a means for the network to modulate its activity regardless of other factors that may be affecting the period. For example, the heartbeat of juvenile leeches is significantly faster than that of adults (Wenning et al., 2004). Both juvenile and adult leeches could therefore use $\bar{g}_{\mathrm{h}}$ and $\tau_{\mathrm{h}}$ to modulate their heart rate.
When $\bar{g}_{\mathrm{h}}$ was at canonical/normal values or smaller, we observed many cases in which $I_{\mathrm{h}}$ reached its maximal level of activation in the varied neuron long before a burst transition occurred, indicating that no transition was possible until spike frequency of the opposite interneuron declined to a low enough level to reduce inhibition in the varied neuron to the point that it could be overcome by the fully activated $I_{\mathrm{h}}$ (Figs. 6-9). When $\bar{g}_{\mathrm{h}}$ was increased, however, $I_{\mathrm{h}}$ reached its maximal level of activation at or just before the burst transition in the varied neuron; this did not represent a change in the amount of time necessary for $I_{\mathrm{h}}$ to activate but rather the higher final frequency that could be overcome. These results indicate that time course of inactivation of the lowthreshold slowly inactivating $\mathrm{Ca}^{2+}$ current that supports the burst (Angstadt and Calabrese, 1991; Hill et al., 2001) is critical in determining the burst duration of a heart interneuron and thus the period of a half-center oscillator, a hypothesis that may be tested in future hybrid system experiments.

In conclusion, we demonstrated that a hybrid system composed of both biological and modeled neurons can produce realistic activity, and that alterations in the properties of the model neuron accurately reflect similar alterations of the biological neuron. Furthermore, we have demonstrated how $I_{\mathrm{h}}$ can serve as a regulator of network activity, with increasing levels of $I_{\mathrm{h}}$ decreasing cycle period and increasing the duty cycle of affected neurons.

\section{References}

Angstadt JD, Calabrese RL (1991) Calcium currents and graded synaptic transmission between heart interneurons of the leech. J Neurosci 11:746-759.

Bal T, McCormick DA (1997) Synchronized oscillations in the inferior olive are controlled by the hyperpolarization-activated cation current $\mathrm{I}(\mathrm{h})$. J Neurophysiol 77:3145-3156.

Bower JM, Beeman D (1998) The book of GENESIS, Ed 2: exploring realistic neural models with the GEneral NEural SImulation System. New York: Springer-Verlag.

Calabrese RL, Nadim F, Olsen ØH (1995) Heartbeat control in the medicinal leech: a model system for understanding the origin, coordination, and modulation of rhythmic motor patterns. J Neurobiol 27:390-402.

Cymbalyuk G, Gaudry Q, Masino MA, Calabrese RL (2002a) Bursting in leech heart interneurons: cell-autonomous and network-based mechanisms. J Neurosci 22:10580-10592.

Cymbalyuk G, Sorensen M, Simoni MF, DeWeerth SP, Calabrese RL (2002b) Software tools for hybrid systems analysis. Soc Neurosci Abstr 28:67.9.

Derjean D, Bertrand S, Le Masson G, Landry M, Morisset V, Nagy F (2003) Dynamic balance of metabotropic inputs causes dorsal horn neurons to switch functional states. Nat Neurosci 6:274-281.

Douglas R, Rasche C (2002) Silicon neurons. In: The handbook of brain theory and neural networks (Arbib M, ed), pp 1034-1039. Cambridge, MA: MIT.

Goldman M, Golowasch J, Marder E, Abbott LF (2001) Global structure, 
robustness, and modulation of neuronal models. J Neurosci 21:5229-5238.

Harris-Warrick RM, Coniglio LM, Levini RM, Gueron S, Guckenheimer J (1995) Dopamine modulation of two subthreshold currents produces phase shifts in activity of an identified motoneuron. J Neurophysiol 74:1404-1420.

Hill AA, Lu J, Masino MA, Olsen ØH, Calabrese RL (2001) A model of a segmental oscillator in the leech heartbeat neuronal network. J Comput Neurosci 10:281-302.

Hill AA, Van Hooser SD, Calabrese RL (2003) Half-center oscillators underlying rhythmic movements. In: The handbook of brain theory and neural networks (Arbib M, ed), pp 507-510. Cambridge, MA: MIT.

Hodgkin AL, Huxley AF (1952) A quantitative description of membrane current and its application to conduction and excitation in nerve. J Physiol (Lond) 117:500-544.

Kiehn O, Harris-Warrick RM (1992) 5-HT modulation of hyperpolarization-activated inward current and calcium-dependent outward current in a crustacean motor neuron. J Neurophysiol 68:496-508.

Le Masson G, Le Masson S, Moulins M (1995) From conductances to neural network properties: analysis of simple circuits using the hybrid network method. Prog Biophys Mol Biol 64:201-203.

Le Masson G, Renaud-Le Masson S, Debay D, Bal T (2002) Feedback inhibition controls spike transfer in hybrid thalamic circuits. Nature 417:854-858

Le Masson S, Laflaquiere A, Bal T, Le Masson G (1999) Analog circuits for modeling biological neural networks: design and applications. IEEE Trans Biomed Eng 46:638-645.

Luthi A, McCormick DA (1998) H-current: properties of a neuronal and network pacemaker. Neuron 21:9-12.

Maccaferri G, McBain CJ (1996) The hyperpolarization-activated current (Ih) and its contribution to pacemaker activity in rat CA1 hippocampal stratum oriens-alveus interneurones. J Physiol (Lond) 497:119-130.

MacLean JN, Zhang Y, Johnson BR, Harris-Warrick RM (2003) Activityindependent homeostasis in rhythmically active neurons. Neuron 37:109-120.

Mahowald M, Douglas R (1991) A silicon neuron. Nature 354:515-518.

Manor Y, Nadim F (2001) Synaptic depression mediates bistability in neuronal networks with recurrent inhibitory connectivity. J Neurosci 21:9460-9470.

McCormick DA, Huguenard JR (1992) A model of the electrophysiological properties of thalamocortical relay neurons. J Neurophysiol 68:1384-1400.

Nadim F, Manor Y (2001) Frequency regulation demonstrated by coupling a model and a biological neuron. Neurocomputing 38- 40:269-278.

Nadim F, Olsen ØH, De Schutter E, Calabrese RL (1995) Modeling the leech heartbeat elemental oscillator. I. Interactions of intrinsic and synaptic currents. J Comput Neurosci 2:215-235.

Olsen, ØH, Calabrese RL (1996) Activation of intrinsic and synaptic currents in leech heart interneurons by realistic waveforms. J Neurosci 16:4958-4970

Pape HC (1996) Queer current and pacemaker: the hyperpolarizationactivated cation current in neurons. Annu Rev Physiol 58:299-327.
Patel GN, DeWeerth SP (1997) Analogue VLSI Morris-Lecar neuron. Electron Lett IEEE 33:997-998.

Patel GN, Cymbalyuk GS, Calabrese RL, DeWeerth SP (1999) Bifurcation analysis of a silicon neuron. In: Neural information processing systems 12 (Solla SA, Leen TK, Müller K-R, eds), pp 731-737. Cambridge, MA: MIT.

Rasche C, Douglas R (2000) An improved silicon neuron. Analog Integr Circuits Signal Process 23:227-236.

Rasche C, Douglas R, Mahowald M (1998) Characterization of a pyramidal silicon neuron, neuromorphic systems: engineering silicon. In: Neurobiology (Smith LS, Hamilton A, eds), pp 169-177. Teaneck, NJ: World Scientific.

Renaud-LeMasson S, LeMasson G, Marder E, Abbott LF (1993) Hybrid circuits of interacting computer model and biological neurons. In: Neural information processing systems 5 (Hanson SJ, Cowan JD, Giles CL, eds), pp 813-819. San Mateo, CA: Morgan Kauffman.

Robinson RB, Siegelbaum SA (2003) Hyperpolarization-activated cation currents: from molecules to physiological function. Annu Rev Physiol 65:453-480.

Schmidt J, Calabrese RL (1992) Evidence that acetylcholine is an inhibitory transmitter of heart interneurons in the leech. J Exp Biol 171:329-347.

Sharp AA, O’Neil MB, Abbott LF, Marder E (1993) Dynamic clamp: computer-generated conductances in real neurons. J Neurophysiol 69:992-995.

Sharp AA, Skinner FK, Marder E (1996) Mechanisms of oscillation in dynamic clamp constructed two-cell half-center circuits. J Neurophysiol 76:867-883.

Simoni M, Sorensen M, Cymbalyuk G, Calabrese R, DeWeerth S (2002) Control of bursting properties in a silicon neuron CPG. Neurocomputing $44-46$.

Simoni M, Cymbalyuk G, Sorensen M, Calabrese R, DeWeerth S (2004) A multi-conductance silicon neuron with biologically matched conductances. IEEE Trans Biomed Eng 51:342-354.

Szucs A, Varona P, Volkovskii AR, Abarbanel HD, Rabinovich MI, Selverston AI (2000) Interacting biological and electronic neurons generate realistic oscillatory rhythms. NeuroReport 11:563-569.

Thoby-Brisson M, Telgkamp P, Ramirez JM (2000) The role of the hyperpolarization-activated current in modulating rhythmic activity in the isolated respiratory network of mice. J Neurosci 20:2994-3005.

Wang J, Chen S, Nolan MF, Siegelbaum SA (2002) Activity-dependent regulation of HCN pacemaker channels by cyclic AMP: signaling through dynamic allosteric coupling. Neuron 36:451-461.

Wenning A, Cymbalyuk G, Calabrese R (2004) Heartbeat control in leeches I. Constriction pattern and neural modulation of blood pressure in intact animals. J Neurophysiol 91:382-396.

Yarom Y (1991) Rhythmogenesis in a hybrid system-interconnecting an olivary neuron to an analog network of coupled oscillators. Neuroscience 44:263-275.

Zhang Y, Oliva R, Gisselmann G, Hatt H, Guckenheimer J, Harris-Warrick RM (2003) Overexpression of a hyperpolarization-activated cation current $(\mathrm{h})$ channel gene modifies the firing activity of identified motor neurons in a small neural network J Neurosci 23:9059-9067. 